\title{
Health-care-seeking behaviour among university students in Lebanon
}

\author{
H.A. El Kahi, ${ }^{1}$ G.Y. Abi Rizk, ${ }^{7}$ S.A. Hlais ${ }^{7}$ and S.M. Adib ${ }^{7}$
}

$$
\begin{aligned}
& \text { سلوك الِِِِّ|س الرعاية الصحية بين طلبة الجحامعة في لبنان }
\end{aligned}
$$

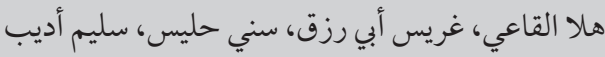

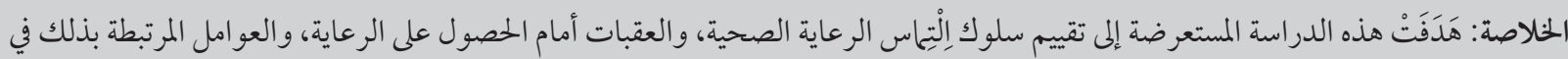

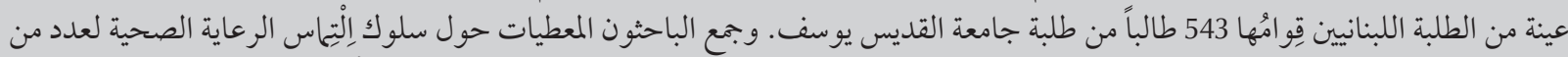

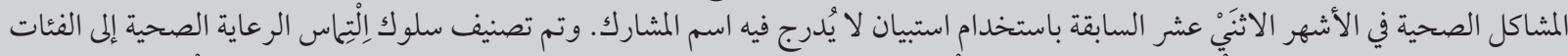

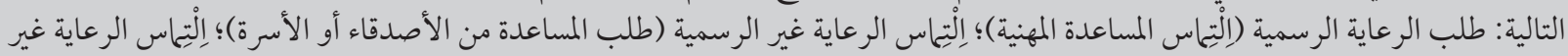

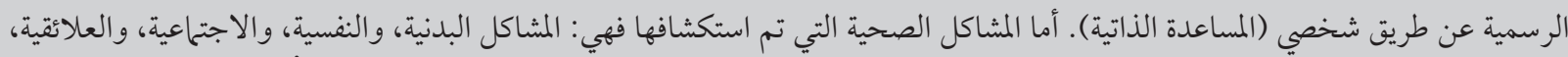

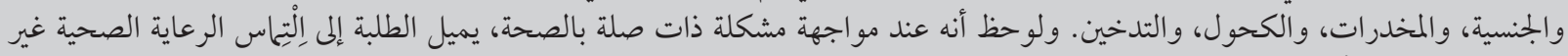

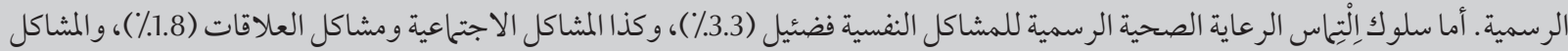

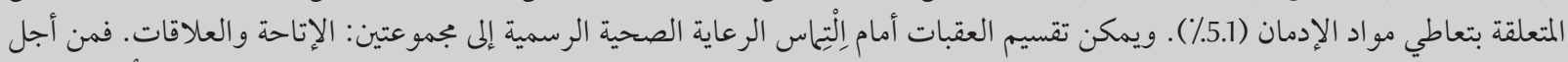

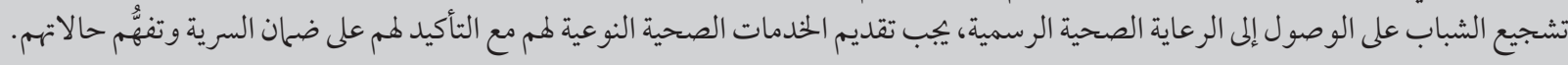

ABSTRACT This cross-sectional study assessed the health-care-seeking behaviour, barriers to accessing care and associated factors among a sample of 543 Lebanese students at Saint-Joseph University. Data were collected on health-care-seeking behaviour for health issues in the previous 12 months using an anonymous questionnaire. Health-care-seeking behaviour was categorized as: formal (professional help sought); informal relational (help sought from friends/family); informal personal (self-help). The health issues examined were: physical, psychological, social and relational, sexual, drug, alcohol and smoking. When facing health-related issues, the students tended to seek informal health care. Formal health-care-seeking behaviour was almost non-existent for psychological issues $(3.3 \%)$, relational and social issues (1.8\%), and issues related to substance use (5.1\%). The barriers to seeking formal health care fell into 2 categories: accessibility and relational. To encourage young people to access formal health care, specific health services should be provided for them where they are assured of confidentiality and understanding.

\section{Comportement en matière de recherche de soins des étudiants d'une université au Liban}

RÉSUMÉ La présente étude transversale a évalué le comportement de recherche de soins de santé d'un échantillon de 543 étudiants libanais inscrits à l'Université Saint-Joseph, les obstacles à l'accès aux soins et les facteurs associés en la matière. Les données ont été recueillies sur le comportement de recherche de soins pour des problèmes de santé dans les 12 mois précédents au moyen d'un questionnaire anonyme. Les comportements de recherche de soins ont été catégorisés comme suit : formel (recherche d'une aide professionnelle); relationnel informel (recherche d'une aide auprès d'amis/de la famille); personnel informel (recherche individuelle). Les problèmes de santé étudiés étaient d'ordre physique, psychologique, social/relationnel, sexuel, toxicologique, alcoolique et tabagique. Face à des problèmes de santé, les étudiants avaient tendance à rechercher des soins de santé informels. Le comportement de recherche de soins formel était presqu'inexistant pour les problèmes d'ordre psychologique $(3,3 \%)$, relationnel et social $(1,8 \%)$, ainsi que pour les questions liées à l'usage de substances psychoactives $(5,1 \%)$. Deux types d'obstacles à une recherche de soins de santé formelle sont apparus : l'accessibilité et les relations. Pour encourager les jeunes à accéder aux soins de santé formels, des services de santé dédiés devraient leur être offerts. afin qu'ils soient assurés du caractère confidentiel de la consultation et de la compréhension des professionnels. 


\section{Introduction}

The "youth" constitutes a population subgroup with lower rates of mortality, morbidity and medical use. Nevertheless, they tend to have significant health concerns that are often hidden and/or under-diagnosed, and these may relate to risky behaviours such as drug and alcohol abuse, unsafe sexual behaviours, smoking, and mental health issues such as depression and suicidal thoughts and attempts [1-4].

Young people tend to find it difficult to ask for help especially when it comes to health issues; the major barriers to accessing health services include concerns about confidentiality, embarrassment in disclosing health issues [5-8], absence of medical insurance or limited financial accessibility [5,7-10], low knowledge of existing services and lack of trust in health professionals $[7,8]$. Thus, whenever young people face health concerns, they often seek health care informally; in other words, they do not refer to health professionals or to formal health services first. Instead, they are more likely to seek help from people close to them: parents, friends or others they trust $[6,7,11]$. Furthermore, the need for autonomy that defines youth generates self-help practices based on Internet browsing [12] or self-medication [13]. Health-care-seeking behaviour among young people is also partially affected by their socioeconomic status and the cost of health services [11], urban or rural origins $[9,10,14,15]$ as well as gender, young women are more likely to seek help from health providers than young men. $[5,7,9,10,14-17]$.

In Lebanon, studies have also shown that Lebanese youth may also participate in risky behaviour, such as drug and alcohol use [18], and have suicidal thoughts [19]. Despite this, health interventions targeting young adults are not a priority for health policies in Lebanon [20], hence services specifically provided for young adults and their needs are very rare and may be limited to university-based health services. As in other countries, young people in Lebanon tend to engage in informal health-care-seeking behaviour rather than resort to formal health structures [21]. Young people aged between 10 and 20 years have the lowest use of ambulatory care and of routine consultations [22].

This study attempts to explain the health-care-seeking behaviour among adolescents entering university and the barriers to formal care-seeking. This in turn may suggest ways to improve the outreach to young people and increase their use of formal health services.

\section{Methods}

\section{Design and target population}

A cross-sectional survey targeted students of Saint-Joseph University (USJ) undergoing their mandatory preventive medical visit at the University Center of Family and Community Health (UCFCH). UCFCH organizes yearly preventive health visits intended for all first-year students from the Beirut, Tripoli, Saida and Zahle campuses. These visits take place during the first and second semester of each academic year.

Our sample comprised all the students aged 17 to 21 years undergoing their preventive medical visit in UCF$\mathrm{CH}$ during the second semester of the academic year 2007-2008 (between 1 January 2008 and 31 May 2008).

\section{Survey questionnaire}

A questionnaire partially based on similar studies found in the medical literature [7-9,11,12], was pilot-tested with about 50 students and modified accordingly. Questionnaires were anonymous and designed to be self-completed in approximately 10 minutes. They were given by hand to the students by the nurses of the Center before the preventive medical visit. The students completed them on the spot and returned them to the nurses. The purpose of the study was explained in the introduction to the questionnaire and nurses were available for further clarification.

\section{Definition of variables}

Two dependent variables were measured: health-care-seeking behaviour and barriers to formal care

Health-care-seeking behaviour was defined as: formal, when professional help was sought from health care services and/or health care providers (physicians, psychologists); informal relational, when help was sought from members of the student's social network (parents, friends, teachers, trusted persons); informal personal, when young people resorted to self-medication or browsed the Internet or read self-help books.

The type of health-care-seeking behaviour recorded for each student was that most frequently reported when faced by various categories of health issues in the previous 12 months. These health issues were divided into 5 categories and listed in the questionnaire as follows:

- Physical issues, acute or chronic, such as headaches, stomach aches, cough, acne, obesity, diabetes, asthma

- Psychological issues, such as anxiety, stress, low mood, depression

- Social and relational issues, such as conflicts with parents, difficulties making friends, difficulties in studies

- Sexual issues, such as sexually transmitted diseases, contraception

- Drug, alcohol and smoking issues.

When a participant indicated both formal and informal behaviour equally regarding any one category of problem, he/she was classified as engaging in formal behaviour. A category of "no careseeking behaviour" was subsequently created for those who reported health problems yet declared not taking any remediation steps.

Barriers to formal care was assessed according to 8 possible barriers to using 
formal care, measured on 3-point Likert scales. Later, principal component analysis of those 8 items found 2 categories of barriers: accessibility and relational barriers.

The independent variables considered in this analysis were:

- Age, categorized as $17-18$ or 19-21 years

- Sex

- Household crowding index (HCI), defined as the total number of residents per household divided by the total number of rooms, excluding the kitchen and bathrooms. $\mathrm{HCI}$ is a correlate of socioeconomic status as demonstrated by the study of Melki et al. [23]. It is a continuous variable that decreases as we move from low to high socioeconomic status.

- Father's and mother's levels of education, categorized as lower than university or university and above

- Place of residence as reported by the student, categorized as rural, urban or suburban (in between urban and rural, e.g. small towns).

\section{Ethical considerations}

The objectives and procedures of the study were submitted to the Ethical Committee of Saint-Joseph University. It was made clear that the study would be anonymous, that the consent of the students would be sought to participate, and that non-participation would not be penalized. Ethical approval was subsequently granted.

\section{Statistical analysis}

Categorical variables were tabulated as frequencies and percentages and continuous variables as means, medians and standard deviation (SD). The associations between dependent and independent variables were tested using: chi-squared test, $t$-test and ANOVA. Independent variables with significant bivariate association with the dependent variables were subsequently entered in a multivariate logistic regression analysis to determine their joint effects on the outcomes and the odds ratio (OR) and 95\% confidence intervals (95\% CI) were determined. Differences were considered statistically significant for $P \leq 0.05$. Data were analysed using SPSS, version 13.0 for Windows and STATA 7.

\section{Results}

\section{Sociodemographic characteristics}

Table 1 shows the sociodemographic characteristics of the students. In total 543 students were invited to participate, 22 (4\%) of whom declined to take part. Of the 521 students who completed a questionnaire, 315 (60\%) were women and $206(40 \%)$ men. The mean age was 18.5 (SD 0.8) years. The majority of the participants were either urban or suburban residents, only $12.1 \%$ were rural residents. The parents' level of education was relatively high: $60 \%$ of fathers and 52\% of mothers had university degree or above. The socioeconomic status of the students as measured by the HCI, was predominantly middle class, as indicated by a mean index of 1 person/room.

\section{Health status}

Table 2 shows the reported health status of the students. Only 57 students (10.9\%) said they had had no health problem in the 12 months prior to the survey, significantly more in men than women $(P<0.001)$. The health problems most frequently mentioned in the previous 12 months were physical issues (71.6\%), psychological issues (57.2\%). Significantly more women reported physical and psychological issues than men $(P<0.004)$, while more men reported drug, alcohol and smoking issues $(P<0.001)$.

\section{Health-care-seeking behaviour}

For the students who reported having faced physical issues, $61.9 \%$ sought

\begin{tabular}{lc}
\hline Table 1 Sociodemographic characteristics of surveyed university students \\
\hline Variable & $\begin{array}{c}\text { No. }(\%) \\
(\boldsymbol{n}=521)\end{array}$ \\
\hline Sex & $206(39.5)$ \\
$\quad$ Male & $315(60.5)$ \\
$\quad$ Female & \\
Age (years) & $280(53.8)$ \\
17-18 & $241(46.2)$ \\
19-21 & $18.6(0.8) ; 20(17-21)$ \\
$\quad$ Mean (SD); Median (range) (years) & $208(40.0)$ \\
Father's education & $312(60.0)$ \\
$\quad$ Less than university & \\
$\quad$ University and higher & $249(47.9)$ \\
Mother's education & $271(52.1)$ \\
$\quad$ Less than university & \\
$\quad$ University and higher & $255(48.9)$ \\
Region of residence & $203(39.0)$ \\
Urban & $63(12.1)$ \\
Suburban & \\
Rural (small town or village) & \\
Crowding index (number of persons/room) & $(0.4), 0.9(0.2-2.5)$ \\
$\quad$ Mean (SD); Median (range) &
\end{tabular}

$S D=$ standard deviation. 


\begin{tabular}{lcccc}
\hline \multicolumn{1}{l}{ Table 2 Frequency of health issues in the last $\mathbf{1 2}$ months reported by the university students according to sex } \\
\hline Health issue & $\begin{array}{c}\text { Females } \\
(\boldsymbol{n}=315) \\
\text { No. }(\%)\end{array}$ & $\begin{array}{c}\text { Males } \\
(\boldsymbol{n}=\mathbf{2 0 6})\end{array}$ & $\begin{array}{c}\text { Total } \\
(\boldsymbol{n}=\mathbf{5 2 1})\end{array}$ & $\boldsymbol{P}$-value \\
& $244(77.5)$ & $129(62.6)$ & $373(71.6)$ & $<0.001$ \\
Physical & $196(62.2)$ & $102(49.5)$ & $298(57.2)$ & 0.004 \\
Psychological & $60(19.0)$ & $49(23.8)$ & $109(20.9)$ & 0.194 \\
Social \& relational & $60(19.0)$ & $29(14.1)$ & $89(17.1)$ & 0.141 \\
Sexual & $21(6.7)$ & $38(18.4)$ & $59(11.3)$ & $<0.001$ \\
Drugs, alcohol \& smoking & $6(1.9)$ & $6(2.9)$ & $12(2.3)$ & 0.454 \\
Other issues & $22(7.0)$ & $35(17.0)$ & $57(10.9)$ & $<0.001$ \\
No issues & & & &
\end{tabular}

informal help from a family member or friend (informal relational healthcare-seeking behaviour), while only $35.7 \%$ sought formal health care from a physician or a health facility. As regards psychological issues, and in spite of the high prevalence $(57.2 \%)$, only $3.3 \%$ consulted a health provider or a health facility, while $21.1 \%$ did not seek any help with these issues; the majority of the students $(76 \%)$ sought informal help from a family member or friend, mostly friends.

These results were similar in relation to social and relational issues: only $1.8 \%$ sought formal health care, $32.1 \%$ sought no health care and $64.2 \%$ informally talked to a relation or friend, again mostly friends (Table 3 ). With regard to drug, alcohol and smoking issues, here again seeking formal health care was very rare (5.1\%), the absence of health-care-seeking behaviour was relatively high (22.0\%) and informal relational behaviour was predominant (68\%), mostly friends. As for sexual health related issues, while $57.3 \%$ showed informal relational healthcare-seeking behaviour, informal personal behaviour was relatively more frequent than elsewhere (15.7\%), mostly self-research, as was formal recourse to health providers or health facilities (32.6\%).

Table 4 shows the health-care-seeking behaviour related to physical issues and sexual health issues according to the sociodemographic characteristics of the students. With regard to sexual health issues, more women showed formal behaviour than men $(P<0.01)$ and more students from suburban areas than those from urban areas $(P=0.05)$. These results remained unaltered in the multivariate linear regression model: OR 0.087,95\% CI: 0.018-0.422 for sex and OR $3.408,95 \%$ CI: $1.211-9.595$ for residence.
For other health issues (psychological, social and relational, problems related to drugs, alcohol and smoking), most students exhibited informal health-careseeking behaviour, and comparisons by the independent variables was therefore uninformative.

\section{Barriers to accessing formal health-care-seeking behaviour}

Table 5 shows the barriers to accessing formal health-care-seeking behaviour reported by the university students according to importance. For the 8 barriers to seeking formal health care enquired about in the questionnaire, all but one (other barriers) were considered a barrier by a large majority of the students. However, most regarded them as low importance. Table 6 shows the results of the principal component analysis of barriers to formal health-care-seeking behaviour. Of the 8 possible barriers, principal component analysis found 2 wide categories:

\begin{tabular}{|c|c|c|c|c|c|}
\hline \multirow[t]{3}{*}{ Health issue } & \multicolumn{2}{|c|}{ Informal } & \multirow{3}{*}{$\begin{array}{l}\text { Formalc }^{c} \\
\text { No. (\%) }\end{array}$} & \multirow{3}{*}{$\begin{array}{l}\text { None } \\
\text { No. (\%) }\end{array}$} & \multirow{3}{*}{$\begin{array}{l}\text { Totald }^{d} \\
\text { No. }\end{array}$} \\
\hline & Relational $^{\mathrm{a}}$ & Personal $^{\mathbf{b}}$ & & & \\
\hline & No. (\%) & No. (\%) & & & \\
\hline Physical & $231(61.9)$ & $37(9.9)$ & $133(35.7)$ & $41(11.0)$ & 373 \\
\hline Psychological & $226(75.9)$ & $18(6.0)$ & $10(3.3)$ & $63(21.1)$ & 298 \\
\hline Social \& relational & $70(64.2)$ & $6(5.5)$ & $2(1.8)$ & $35(32.1)$ & 109 \\
\hline Sexual & $51(57.3)$ & $14(15.7)$ & $29(32.6)$ & $10(11.2)$ & 89 \\
\hline Drugs, alcohol \& smoking & $40(67.8)$ & $5(8.4)$ & $3(5.1)$ & $13(22.0)$ & 59 \\
\hline
\end{tabular}

aIncludes recourse to parents and/or friends and/or another person of trust.

${ }^{b}$ Includes recourse to self-medication and/or self-research.

Includes recourse to professional health care providers and/or health facilities.

${ }^{d}$ More than one care-seeking behaviour was possible for each group of health issues. 


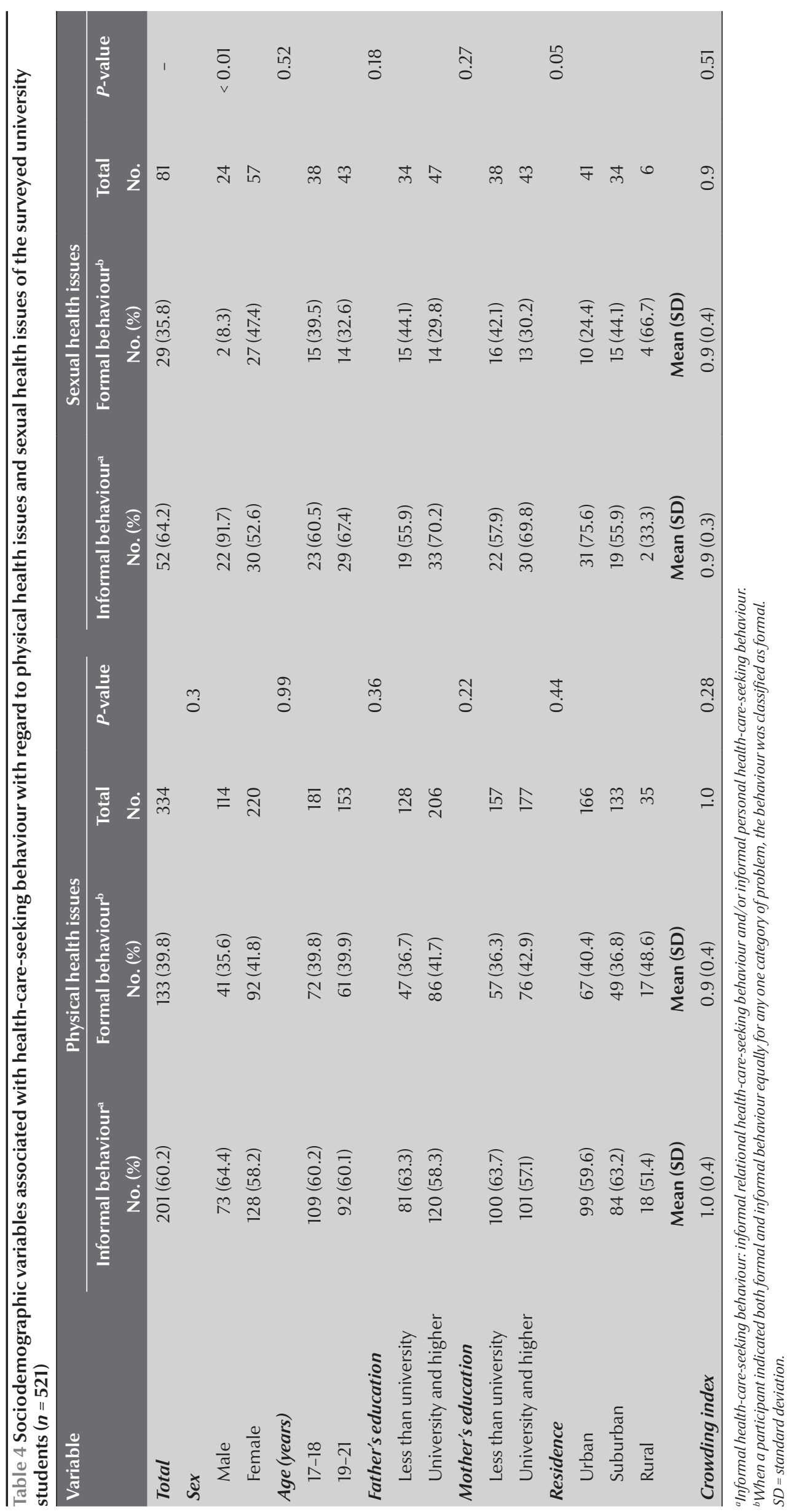




\begin{tabular}{lcrcc}
\hline $\begin{array}{l}\text { Table } 5 \text { Barriers to accessing formal health-care-seeking behaviour in the last 12 months by surveyed university students } \\
\text { Barrier }\end{array}$ & \multicolumn{3}{c}{ Importance of the barrier } & Towal \\
& No. (\%) & No. (\%) & No. (\%) & No. \\
& $275(60.3)$ & $108(23.7)$ & $73(16.0)$ & 456 \\
Knowledge of services & $304(69.4)$ & $98(22.4)$ & $36(8.2)$ & 438 \\
Inadequate transportation means & $269(63.6)$ & $99(23.4)$ & $55(13.0)$ & 450 \\
Concerns about confidentiality towards parents & $291(69.1)$ & $89(21.1)$ & $41(9.7)$ & 421 \\
Difficulties of contact & $252(57.7)$ & $101(23.1)$ & $84(19.2)$ & 437 \\
Cost & $223(51.6)$ & $106(24.5)$ & $103(23.8)$ & 432 \\
Embarrassment in disclosing health concerns & $270(62.4)$ & $80(18.5)$ & $83(19.2)$ & 433 \\
General concerns about confidentiality & $227(55.1)$ & $104(25.2)$ & $81(19.7)$ & 412 \\
Doubt on the ability of professionals to help & $16(66.7)$ & $7(29.2)$ & $1(4.2)$ & 24 \\
Others barriers & & & &
\end{tabular}

- Relational barriers: these were general concerns about confidentiality, concerns about confidentiality towards the parents, embarrassment in disclosing health concerns, and doubt about the ability of professionals to help. These barriers explained $29 \%$ of the variability with an Eigenvalue of 2.30 .

- Accessibility barriers: these were lack of knowledge of services, inadequate means of transportation, difficulties in making contact and cost. These barriers explained $23 \%$ of the variability with an Eigen-value of 1.86.

The potential effects of the independent variables on these 2 categories of barriers were analysed. Table 7 shows the sociodemographic characteristics of the students associated with the relational and accessibility barriers to formal health-care-seeking behaviour. Accessibility obstacles were not affected by any of the independent variables in the study. On the other hand, perceived relational barriers increased significantly with age $(P<0.009)$ and with urban residence $(P<0.017)$. These results remained unaltered in the multivariate linear regression model of sociodemographic variables associated with relational barriers to formal health-careseeking behaviour: coefficient for age
$=0.270(P=0.013)$ and coefficient for residence $=-0.343(P=0.007)$.

\section{Discussion}

Although adolescents are past the care of paediatricians, they have several types of health needs and concerns that cannot be fully met within the adult-oriented care system. While the 17-21-year-old students interviewed were in good health as would be expected, $71.6 \%$ had had some physical concerns in the past year, over a half reported psychological concerns and nearly a quarter had relational concerns. As for sexual

\begin{tabular}{|c|c|c|}
\hline \multirow[t]{2}{*}{ Barrier } & \multicolumn{2}{|c|}{ Loading of each barrier on both factors } \\
\hline & Factor 1 & Factor 2 \\
\hline Knowledge of services & 0.056 & 0.596 \\
\hline Inadequate means of transportation & 0.059 & 0.770 \\
\hline Concerns about confidentiality towards parents & 0.635 & 0.337 \\
\hline Difficulties of contact & 0.358 & 0.468 \\
\hline Cost & 0.412 & 0.648 \\
\hline Embarrassment in disclosing health concerns & 0.746 & 0.263 \\
\hline General concerns about confidentiality & 0.732 & 0.282 \\
\hline \multirow[t]{2}{*}{ Doubt about the ability of professionals to help } & 0.710 & -0.112 \\
\hline & Factor 1: relational barriers ${ }^{\mathrm{a}}$ & Factor 2: accessibility barriers ${ }^{b}$ \\
\hline Eigen value & 2.304 & 1.863 \\
\hline Variance (\%) & 28.796 & 23.284 \\
\hline
\end{tabular}

${ }^{a}$ General concerns about confidentiality, concerns about confidentiality towards the parents, embarrassment in disclosing health concerns, and doubt about the ability of professionals to help.

${ }^{b}$ Knowledge of services, inadequate transport, difficulty of contact and cost. 


\begin{tabular}{|c|c|c|c|c|c|c|}
\hline \multirow[t]{2}{*}{ Variable } & \multicolumn{3}{|c|}{ Relational barriers ${ }^{\mathrm{a}}$} & \multicolumn{3}{|c|}{ Accessibility barriers $^{b}$} \\
\hline & Mean (SD) & $\begin{array}{l}\text { Linear } \\
\text { regression } \\
\text { coefficient }\end{array}$ & $P$-value & Mean (SD) & $\begin{array}{l}\text { Linear } \\
\text { regression } \\
\text { coefficient }\end{array}$ & $P$-value \\
\hline Sex & & & 0.476 & & & 0.827 \\
\hline Male & $6.2(2.1)$ & & & $5.8(1.7)$ & & \\
\hline Female & $6.4(2.0)$ & & & $5.8(1.6)$ & & \\
\hline Age (years) & & 0.115 & 0.009 & & 0.020 & 0.651 \\
\hline Father's levels of education & & & 0.264 & & & 0.999 \\
\hline Less than university & $6.2(2.0)$ & & & $5.8(1.7)$ & & \\
\hline University and higher & $6.4(2.0)$ & & & $5.8(1.6)$ & & \\
\hline Mother's levels of education & & & 0.559 & & & 0.999 \\
\hline Less than university & $6.4(1.9)$ & & & $5.8(1.7)$ & & \\
\hline University and higher & $6.3(2.0)$ & & & $5.8(1.6)$ & & \\
\hline Residence & & & 0.017 & & & 0.075 \\
\hline Urban & $6.5(2.1)$ & & & $5.9(1.6)$ & & \\
\hline Suburban ${ }^{c}$ & $6.2(2.0)$ & & & $5.4(1.2)$ & & \\
\hline Rural & $5.8(1.6)$ & & & $5.8(1.8)$ & & \\
\hline Crowding index (mean perso & s/room) & -0.006 & 0.886 & & 0.083 & 0.060 \\
\hline
\end{tabular}

${ }^{\mathrm{a}}$ General concerns about confidentiality, concerns about confidentiality towards the parents, embarrassment in disclosing health concerns, and doubt on the ability of professionals to help.

${ }^{\mathrm{b}}$ Knowledge of services, inadequate transport, difficulty of contact and cost.

'Small town or village.

$S D=$ standard deviation.

and addictive substances concerns, which are traditionally associated with adolescence, they were less frequently reported. A similar low frequency of sexual and addictive substances concerns was found in a study conducted among Chinese school students [17]. This is lower than reported in North American and western European countries $[1,3]$ and may in part be explained by the different cultural construct in Lebanon, or in China, with regard to such sensitive issues. Topics relating to sexuality and addictive substances are considered taboo in Lebanon and are thus less openly discussed. Additionally, adolescents may ignore or underestimate the health risks associated with such substances, especially tobacco and alcohol, and with risky sexual practices. Therefore they do not consider them real health threats but rather normal behaviour and hence they do not require any intervention.

Faced with different sorts of health concerns, the young people surveyed tended to avoid seeking help from formal health-care providers and turned instead primarily to their peers and other sources of informal help. This was also shown in other studies conducted elsewhere, although the populations studied were younger $[6,7,11]$. Our participants particularly showed informal health-care-seeking behaviour when it came to psychological, relational and addictive substances issues. Furthermore, they were more likely to forego care for these categories of problems, a tendency that has also been found elsewhere [5].

While informal health-care-seeking behaviour was also predominant among our students for physical and sexual health issues, they were more likely to have recourse to a formal and professional source for these issues. The health-care-seeking behaviour resemblance between these 2 issues may indicate that, in the minds of these Lebanese adolescents, the organic/reproductive dimensions of sexuality prevail over the relational/emotional ones. On another level, regarding sexual health issues, young people were more likely to resort to informal personal health-careseeking behaviour than for the other issues, meaning that they looked for information by Internet browsing or by reading books and magazines.

It is also worth noting that when young people sought informal relational help, the choice of the person approached depended on the nature of the health concern. Young people went to their parents when the problems were of a bodily nature, physical and sexual problems, which may ultimately require formal medical care. They were more likely to go to friends for emotional or behavioural problems. These observations are similar to results found elsewhere. In Chili, for example, with physical problems, 1 out of 3 teenagers asked their parents for help, 1 out of 10 asked a health professional 
and very few asked friends for help. For personal problems, 1 teenager in 3 asked for friends' help and less than 1 in 100 asked for a doctor's help [24]. In Switzerland, recourse to family was first in terms of physical problems and to friends for psychological problems [25]. In France, teenagers preferred to talk to their mothers when it came to general health problems, while they preferred to talk to their friends for emotional or relational problems [11].

Gender differences were noted in our study and these should be taken into consideration when dealing with the youth in Lebanon. Female students had more physical and psychological issues, while male students reported more issues related to addictive substances. In previous studies conducted in the United States $[5,9,10,14,16]$, Australia $[7,15]$ and China [17], girls expressed a greater willingness than boys to access a service. In our study, however, gender differences were only evident for sexual health issues, with females showing more formal behaviour than males. This could be explained by the fact that young women, naturally preoccupied by reproductive health issues such as contraception and menstruation, tend to seek professional help more frequently than men, for whom these issues tend to be of lower importance. Furthermore, a culture of self-reliance related to males may make them reluctant to seek formal care.

While in general, youth in rural communities tend to forego formal care more frequently than in urban settings $[9,10,14,15]$, the only rural-urban differences we found also concerned sexual health issues: young people from a rural or semi-rural residence reported more formal health-care-seeking behaviour than those from an urban residence. This might be because the students from rural areas consider their parents and friends poorly informed about sexual issues and hence unqualified to help them. It might also reflect the relational closeness in rural social networks so that a young person is reluctant to share "embarrassing" information with friends or relatives, fearing its rapid disclosure to the entire network. Professional health practitioners are thus perceived as nonjudgemental and more discreet sources to turn to for advice and help.

The common barriers to care reported by our students are similar to those reported elsewhere [5,7-10], suggesting that these are universal and transcend geographical differences. The majority cited both accessibility and relational barriers. The survey did not elicit whether these concerns were based on previous unsatisfactory experiences or whether they were just unfounded beliefs. At any rate, this finding indicates the need to reassure young adults coming in contact with formal care and to provide more intimacy and certainty of confidentiality than usually provided to adult patients.

Although many studies have shown that adolescents from rural areas have more difficulty in accessing health care $[9,10,14,15]$, we did not find any rural-urban differences concerning accessibility. As for relational barriers, such as concerns about confidentiality and embarrassment, they tended to increase with age and within urban areas. It may be that with age or when from an urban area, young people become more reserved about their relations, want more intimacy and confidentiality, and have higher expectations from health providers.

Informal care-seeking behaviour is a reality that health professionals concerned with youth health cannot ignore. Health professionals should be aware of these trends and reach out to adolescents. First, they should provide young people with specific services, which are multidisciplinary, adapted to their needs/expectations and affordable, and ensure that they know about them by, for example, using the Internet as a means to reach out to them. Second, health professionals need to work on establishing a solid partnership of trust with adolescents and make them feel more comfortable with disclosing intimate concerns and assured of confidentiality. Third, care does not always have to be given by formal health-care providers; informal providers are also a good means to deliver proper care to youth. Nevertheless, informal care is not always appropriate and health professionals need to support and educate parents, peers and other support networks so that they can have a better impact on youth health. More research, including qualitative studies, should be encouraged to further understand the contextual triggers that may push young people to consult (or not) their physician or psychologist. These may be more amenable to modification than unalterable factors such as gender or area of residence.

\section{Acknowledgements}

This study was funded by the Saint Joseph University Research Council.

\section{References}

1. Wauquiez L. La santé et la protection sociale des étudiants. Rapport d'information 3494. [Health and welfare of students. Information report 3494]. Paris, Assemblée Nationale (Fr), Commission des Affaires Culturelles, Familiales et Sociales National Assembly ( $\mathrm{Fr}$ ) [Commission of Cultural, Family and Social Affairs], 2006.
2. Roberts RE, Lewinsohn PM, Seeley JR. Symptoms of DSM-III-R major depression in adolescence: evidence from an epidemiological survey. Journal of the American Academy of Child and Adolescent Psychiatry, 1995, 34:1608-1617.

3. Coiro MJ, Zill N, Bloom B. Health of our nation's children. Vital and Health Statistics, 1994, (191):1-61. 
4. Baromètre santé 2000 - Les comportements des 12-25 ans [Health barometer 2000 - the behaviours of 12-25-year-olds]. Paris, Institut National de la Prévention et d'Education pour la Santé, 2004.

5. Zimmer-Gembeck MJ, Alexander T, Nystrom RJ. Adolescents report their need for and use of health care services. Journal of Adolescent Health, 1997, 21:388-399.

6. Pommier J et al. Self-reported determinants of health service use by French adolescents. International Journal of Adolescent Medicine and Health, 2001, 13:115-129.

7. Booth $\mathrm{ML}$ et al. Access to health care among Australian adolescents young people's perspectives and their sociodemographic distribution. Journal of Adolescent Health, 2004, 34:97-103.

8. Elliott BA, Larson JT. Adolescents in mid-sized and rural communities: foregone care, perceived barriers, and risk factors. Journal of Adolescent Health, 2004, 35:303-309.

9. Klein JD, McNulty M, Flatau CN. Adolescents' access to care: teenagers' self-reported use of services and perceived access to confidential care. Archives of Pediatrics \& Adolescent Medicine, 1998, 152:676-682.

10. Ford CA, Bearman PS, Moody J. Foregone health care among adolescents. JAMA: Journal of the American Medical Association, 1999, 282:2227-2234.

11. Pommier J et al. Attitudes à l'égard des soins formels et informels : comparaison d'adolescents français et chiliens [Attitudes regarding the delivery of formal and informal care: comparison of French and Chilean adolescents]. Santé Publique, 2002, 14:371-387.

12. Gould MS et al. Seeking help from the internet during adolescence. Journal of the American Academy of Child and Adolescent Psychiatry, 2002, 41:1182-1189.

13. Pommier J et al. French adolescent attitudes towards informal care for physical and emotional or relational problems. Acta Paediatrica (Oslo, Norway), 2002, 91(4):466-474.

14. Newacheck PW et al. Adolescent health insurance coverage: recent changes and access to care. Pediatrics, 1999, 104:195-202.

15. Quine $S$ et al. Health and access issues among Australian adolescents: a rural-urban comparison. Rural and Remote Health, 2003, 3:245.
16. Marcell AV et al. Male adolescent use of health care services: where are the boys? Journal of Adolescent Health, 2002, 30:35-43.

17. Hesketh T, Ding QJ, Tomkins AM. Health and health careseeking behavior of adolescents in urban and rural China. Journal of Adolescent Health, 2003, 33:271-274.

18. Institut de Gestion de la Santé et de la Protection Sociale (IGSPS) [Institute of Health Management and Social Protection]. Recueil national des statistiques sanitaires au Liban [National health statistics in Lebanon]. Beirut, Saint-Joseph University, 2004.

19. Sibai A, Kanaan N. Youth health risk behaviour survey among secondary school students in Lebanon: Prevalence and clustering of risk behaviours. Beirut, World Health Organization Regional Office for the Eastern Mediterranean, 1999.

20. A picture of health: a review and annotated bibliography of the health of young people in developing countries. Geneva, World Health Organization, 1995.

21. El-Kak FH et al. High school students in postwar Lebanon: attitudes, information sources, and perceived needs related to sexual and reproductive health. Journal of Adolescent Health, 2001, 29:153-155

22. Kasparian G, Ammar W. L'enquête nationale sur les dépenses et l'utilisation des services de santé par les ménages en 1999,Vol 1 [The national survey on spending and use of health services by households in 1999, Vol 1]. Beirut, Ministry of Public Health, 2001

23. Melki IS et al.National Collaborative Perinatal Neonatal Network (NCPNN). Household crowding index: a correlate of socioeconomic status and inter-pregnancy spacing in an urban setting. Journal of Epidemiology and Community Health, 2004, 58:476-480

24. Florenzano-Urzua R. El adolescente y sus conductas de riesgo [Adolescent risk behaviour]. Santiago, Ediciones Universidad Catolica de Chile, 1997.

25. Michaud PA et al. Recherche romande sur la santé des adolescents de 15 à 20 ans [Health survey of 15-20-year-old adolescents in French-speaking Switzerland]. Schweizerische Medizinische Wochenschrift, 1993, 123:1883-1895. 